\title{
Design of Cold-Mixed High-Toughness Ultra-Thin Asphalt Layer towards Sustainable Pavement Construction
}

\author{
Jiangmiao Yu ${ }^{1,2}$, Nikun Yang ${ }^{1,2}$, Fuda Chen ${ }^{1,2}$, Yanlin Chen ${ }^{1}$, Zhuohan Lin ${ }^{1}$ and Huayang Yu ${ }^{1,2,3, *}$ \\ 1 School of Civil Engineering and Transportation, South China University of Technology, \\ Guangzhou 510641, China; yujm@scut.edu.cn (J.Y.); 201820107505@mail.scut.edu.cn (N.Y.); \\ ctchenfuda@mail.scut.edu.cn (F.C.); 202021010337@mail.scut.edu.cn (Y.C.); \\ 201830181314@mail.scut.edu.cn (Z.L.) \\ 2 Central Fortune Creation (Canton) Roadway Technology Co., Ltd., Foshan 528200, China \\ 3 National Engineering Laboratory of Highway Maintenance Technology, Changsha University of Science \& \\ Technology, Changsha 410114, China \\ * Correspondence: huayangyu@scut.edu.cn; Tel.: +86-188-9883-7614
}

Citation: Yu, J.; Yang, N.; Chen, F.; Chen, Y.; Lin, Z.; Yu, H. Design of Cold-Mixed High-Toughness Ultra-Thin Asphalt Layer towards Sustainable Pavement Construction. Buildings 2021, 11, 619. https:// doi.org/10.3390/buildings11120619

Academic Editor: Emilio Bastidas-Arteaga

Received: 17 October 2021

Accepted: 3 December 2021

Published: 6 December 2021

Publisher's Note: MDPI stays neutral with regard to jurisdictional claims in published maps and institutional affiliations.

Copyright: () 2021 by the authors. Licensee MDPI, Basel, Switzerland. This article is an open access article distributed under the terms and conditions of the Creative Commons Attribution (CC BY) license (https:// creativecommons.org/licenses/by/ $4.0 /)$.

\begin{abstract}
Ultra-thin asphalt overlay has become the mainstream measure of road preventive maintenance due to its good economic benefits and road performance. However, hot mix asphalt concrete technology is widely used at present, which is not the most ideal way to promote energy saving and emission reduction in the field of road maintenance. At the same time, the ultra-thin friction course based on cold mix technology, such as slurry seal layer, micro-surface, and other technologies, are still far behind the hot mix friction course in terms of crack resistance. In this research, by establishing an integrated design of materials and structures, a cold paving technology called "high-toughness cold-mixed ultra-thin pavement (HCUP)" is proposed. The high-viscosity emulsified bitumen prepared by using high-viscosity and high-elasticity modified bitumen is used as the binder and sticky layer of HCUP. The thickness of HCUP is $0.8-2.0 \mathrm{~cm}$, the typical thickness is $1.2 \mathrm{~cm}$, and the nominal maximum size of the coarse aggregate is $8 \mathrm{~mm}$. Indoor tests show that HCUP- 8 has water stability, anti-skid performance, high temperature performance, peeling resistance, and crack resistance that are not weaker than traditional hot-mixed ultra-thin wear layers such as AC-10, Novachip, and GT-8. At the same time, the test road paving further proved that HCUP-8 has excellent road performance with a view to providing new ideas for low-carbon and environmentally friendly road materials.
\end{abstract}

Keywords: ultra-thin pavement; cold-mixed asphalt concrete; crack resistance; design and performance

\section{Introduction}

The ultra-thin asphalt wear layer is a road surface overlay technology that focuses on improving the functional performance of roads, and it is also one of the most promising road preventive maintenance technologies at present [1-3]. The thickness of the ultra-thin asphalt wear layer is only $1 / 3 \sim 1 / 2(\leq 25 \mathrm{~mm})$ of the traditional asphalt overlay [4]. It can efficiently improve the road surface smoothness, anti-skid performance, and noise reduction effect, as well as repair moderate to mild road diseases [5]. Since the introduction of very thin asphalt concrete (Bétons Bitumineux Trés Minces, BBTM) and ultra-thin asphalt concrete (Bétons Bitumineux Ultra Minces, BBUM) in France in the 1970s [6,7], countries around the world have been competing to develop and apply ultra-thin wear layer technology, including SMA10 in Germany [8], Novachip and OGFC in the United States [9-12], Lastika in Indonesia [13], VTHMAL in the United Kingdom [14], and GT Tech in China [15].

In recent decades, the ultra-thin wear layer has been widely used and has also exposed its own weaknesses. Compared with the traditional wear layer, the ultra-thin wear layer is more prone to fatigue cracking, shoving, raveling and other distress. This is because the thickness of the wear layer is reduced. It leads to the growth of the tensile stress of the 
bottom layer, the fatigue damage rate of the structural layer, and the shear force between the layers [16-18]. In order to enhance the durability and stability of the ultra-thin wear layer, scholars focused on the improvement of asphalt materials and the optimization of the grading design. On the one hand, rubber and SBS are used to modify the bitumen to obtain high-viscosity and high-elastic bitumen [19-25]. On the other hand, the toughness of the mixture is enhanced by improving the gradation and increasing the thickness of the asphalt film [5]. The above two aspects of the research have significantly improved the functional durability of the ultra-thin wear layer. Among them, the high-viscosity and high-elastic modified bitumen is an indispensable key raw material for the realization of the ultra-thin wear layer. However, bitumen materials with higher viscoelastic technical indicators often require higher construction temperatures, and higher requirements for the construction environment and supporting equipment, which are not conducive to the promotion of high-performance ultra-thin wear layers in underdeveloped areas. At the same time, compared with the traditional asphalt wear layer, the ultra-thin wear layer using the hot mix hot paving process only saves part of the raw materials, consumes a large amount of non-renewable energy during the project implementation, and emits a large amount of greenhouse gas and PM2.5 (particles with a diameter of 2.5 microns or less), causing irreversible damage to the ecological environment. In addition, in the process of high temperature storage and mixing, the bitumen is prone to aging due to uneven heating, which also has a certain negative impact on the quality stability of the ultra-thin wear layer.

In view of the technical defects of the hot-mixed ultra-thin wear layer, in order to further improve the social, economic and environmental benefits of the ultra-thin wear layer, various thin layer technologies for low-temperature paving have begun to be developed and applied. Among them, the warm mix ultra-thin wear layer represented by SMC and ECA was applied in China [26-31]. However, the warm mix asphalt mixture still needs to be mixed and paved above $140^{\circ} \mathrm{C}$, which brings very limited environmental benefits. Combined with the advantages of thin layer and normal temperature construction, coldmix thin layer technology has lower energy consumption and lower pollution emission, which is an important development direction for realizing sustainable environmental development and building green highways $[32,33]$. The conventional cold mix pavement was first represented by the slurry seal, and based on its technology, the micro-surface technology was gradually formed through the improvement of materials and processes [34] However, a large number of application practices have proved that early distress, such as raveling and cracks, are prone to occur at the micro-surface, resulting in a rough surface, which reduces the driving service level. Due to the low technical standards of the microsurface, its service life is usually 2 to 3 years, which is far behind the traditional hot-mixed wear layer. Therefore, there are some technical bottlenecks that urgently need to be broken in terms of durability and road quality.

In summary, breaking through the technical shortcomings of the traditional coldmixed ultra-thin wearing layer, and developing low-carbon, environmentally friendly and high-quality cold-mixed ultra-thin wearing layer technology with excellent durability will have broad prospects. In this paper, research on raw material design, grading design, road performance verification, crack resistance evaluation, etc., is carried out, and a hightoughness cold mix ultra-thin pavement technology (HCUP) is proposed. This article first introduces the design elements of HCUP, and then sets the traditional ultra-thin wear layer, such as AC-10, Novachip, and GT-8 as a control group, and comprehensively evaluates HCUP from the two perspectives of conventional road performance and crack resistance. Finally, the implementation process and on-site performance testing of the HCUP test road are briefly introduced in order to provide a reference for the research of high-quality cold-mixed ultra-thin wear layer.

\section{Materials Design of HCUP}

HCUP is an ultra-thin asphalt wear layer technology with a thickness of $0.8-2.0 \mathrm{~cm}$. Mixing high-viscosity emulsified bitumen is used as the cementing material to obtain 
excellent overall binding force of the mixture; spraying high-viscosity emulsified bitumen is used as the waterproof bonding layer to better bond with the underlying layer. A coarse aggregate void filling method is adopted for gradation design to ensure the skeleton structure of the mixture. The simultaneous paving technology is used for physical engineering paving, which effectively protects the waterproof adhesive layer from pollution and greatly improves the construction efficiency.

\subsection{Materials}

The GT-8 special binder (PG100 high-viscosity and high-elasticity modified bitumen, technical indicators see Table 1), which was the result of the research group's previous research [15], is used as the main raw material to prepare high-viscosity emulsified bitumen. The resulting high-viscosity emulsified bitumen has good elastic recovery and rutting resistance performance as well as superior dynamic viscosity. The specific preparation process is as follows:

(1) Mixing high-viscosity emulsified bitumen is composed of $65 \sim 70 \%$ high-viscosity and high-elasticity modified bitumen, 3\% cationic emulsifier, $1 \%$ asphalt stabilizer and $26 \sim 31 \%$ water. Spraying high-viscosity emulsified bitumen is composed of $55 \sim 60 \%$ highviscosity and high-elasticity modified asphalt, $3 \%$ cationic emulsifier, $1 \%$ asphalt stabilizer and $36 \sim 41 \%$ water.

(2) Water is mixed with a cationic emulsifier in proportion and heated to $70{ }^{\circ} \mathrm{C}$ to obtain a soap solution.

(3) The high-viscosity and high-elasticity modified bitumen is heated to $185^{\circ} \mathrm{C}$, melted and mixed with asphalt stabilizer. The high temperature mixing process requires more than $1 \mathrm{~h}$.

(4) The asphalt and soap solution are poured into the emulsifying machine in proportion. After compression, shearing and grinding, the asphalt forms uniform and fine particles, which are stably and uniformly dispersed in the soap solution to prepare highviscosity emulsified bitumen. Table 2 is the technical index of high-viscosity emulsified bitumen.

Table 1. Technical index of the high-viscosity and high-elasticity modified bitumen.

\begin{tabular}{ccccc}
\hline Properties & Units & $\begin{array}{c}\text { Technical } \\
\text { Requirement }\end{array}$ & Test Results & Test Method \\
\hline Penetration $\left(25^{\circ} \mathrm{C}, 5 \mathrm{~s}, 100 \mathrm{~g}\right)$ & $0.1 \mathrm{~mm}$ & $30-50$ & 38 & ASTM D5-06E1 [35] \\
Softening point & ${ }^{\circ} \mathrm{C}$ & $\geq 95$ & 98 & ASTM D36-06 [36] \\
Elastic recovery $\left(25^{\circ} \mathrm{C}\right)$ & $\%$ & $\geq 98$ & 99.5 & ASTM D6084/D6084M-21 [37] \\
Solubility (Trichloroethylene) & $\%$ & $\geq 99$ & 99.8 & ASTM D2042-01 [38] \\
Storage stability & ${ }^{\circ} \mathrm{C}$ & $\leq 2.5$ & 2.1 & ASTM D5-06E1976 [39] \\
Complex shear modulus $\mathrm{G}^{*}$ at $60^{\circ} \mathrm{C}$ & $\mathrm{kPa}$ & $\geq 12$ & 17.94 & ASTM D6373-21A [40] \\
Dynamic viscosity at $60^{\circ} \mathrm{C}$ & $\mathrm{Pa} \cdot \mathrm{s}$ & $\geq 580,000$ & & ASTM D2171-07E1 [41] \\
After short-term aging & & & +0.01 & ASTM D2872-04 [42] \\
Mass loss & $\%$ & $\geq 1.0$ & 83.9 & ASTM D5-06E1 [35] \\
Penetration ratio $\left(25{ }^{\circ} \mathrm{C}\right)$ & $\%$ & $\geq 100$ & & ASTM D7175-15 [43] \\
\hline $\mathrm{G}^{*} /$ sind $\delta 2.2 \mathrm{kPa}$ critical temperature & ${ }^{\circ} \mathrm{C}$ & &
\end{tabular}

The coarse aggregate used in HCUP-8 should be selected from high-quality diabase, basalt and diorite with high abrasion resistance, high adhesion, low water absorption, and low needle flake. Table 3 shows the technical requirements for coarse aggregates.

The fine aggregate used in HCUP-8 is preferably machine-made sand with moderate gradation, hard texture, no weathering, and no impurities. Table 4 shows the technical requirements for fine aggregate. 
Table 2. Technical index of high-viscosity emulsified bitumen.

\begin{tabular}{|c|c|c|c|c|c|c|}
\hline \multirow{2}{*}{ Properties } & \multirow{2}{*}{ Units } & \multicolumn{2}{|c|}{ Technical Requirement } & \multicolumn{2}{|c|}{ Test Results } & \multirow{2}{*}{ Test Method } \\
\hline & & Mixing Type & Spraying Type & Mixing Type & Spraying Type & \\
\hline $\begin{array}{c}\text { Oversize residue }(1.18 \mathrm{~mm} \\
\text { sieve })\end{array}$ & $\%$ & $\leq 0.1$ & $\leq 0.1$ & $\leq 0.1$ & $\leq 0.1$ & AASHTO T59 [44] \\
\hline Particle charge & - & Cation (+) & Cation $(+)$ & Cation (+) & Cation $(+)$ & AASHTO T59 [44] \\
\hline Viscosity & $\mathrm{s}$ & $12-60$ & $12-60$ & 26 & 31 & JTG T0621 [45] \\
\hline \multicolumn{7}{|l|}{ Evaporated residue } \\
\hline Residue content & $\%$ & $\geq 60$ & $\geq 55$ & 62.5 & 57.0 & AASHTO T59 [44] \\
\hline Softening point & ${ }^{\circ} \mathrm{C}$ & $>80$ & $>75$ & 82.7 & 95.0 & ASTM D36-06 [36] \\
\hline Ductility $\left(5^{\circ} \mathrm{C}\right)$ & $\mathrm{cm}$ & $\geq 20$ & $\geq 20$ & 39 & 28 & ASTM D113-07 [46] \\
\hline Solubility & $\%$ & $\geq 97.5$ & $\geq 97.5$ & 99.5 & 99.2 & ASTM D2042-01 [38] \\
\hline Elastic recovery & $\%$ & $\geq 92$ & $\geq 85$ & 99 & 95 & ASTM D6084/D6084M-21 [37] \\
\hline Dynamic viscosity at $60{ }^{\circ} \mathrm{C}$ & $\mathrm{Pa} \cdot \mathrm{s}$ & $\geq 30,000$ & $\geq 20,000$ & 40,625 & 55,174 & ASTM D2171-07E1 [41] \\
\hline Penetration & $0.1 \mathrm{~mm}$ & $40-60$ & $40-60$ & 55 & 58 & ASTM D5-06E1 [35] \\
\hline
\end{tabular}

Table 3. Technical requirements for coarse aggregates.

\begin{tabular}{ccccc}
\hline Properties & Units & $\begin{array}{c}\text { Technical } \\
\text { Requirement }\end{array}$ & Test Results & Test Method \\
\hline Crushing value & & $\leq 18$ & 11.3 & ASTM D5821-13 [47] \\
Abrasion and Impact by Los Angeles Machine & $\%$ & $\leq 20$ & 14.1 & ASTM C131-01 [48] \\
Apparent specific gravity & - & $\geq 2.60$ & 2.926 & ASTM C127-12 [49] \\
Water absorption & $\%$ & $\leq 1.0$ & 0.89 & ASTM C127-12 [49] \\
Soundness & $\%$ & $\leq 12$ & 5.1 & ASTM C88/C88M-18 [50] \\
Flat and elongated particle content & $\%$ & $\leq 1$ & 0.3 & ASTM D4791-19 [51] \\
<0.075 mm particle content & $\%$ & $\geq 42$ & ASTM C136 [52] & ASTM D3319 [53] \\
Polished stone value & $\mathrm{BPN}$ & & &
\end{tabular}

Table 4. Technical requirements for fine aggregates.

\begin{tabular}{ccccc}
\hline Properties & Units & Technical Requirement & Test Results & Test Method \\
\hline Apparent specific gravity & - & $\geq 2.50$ & 2.875 & ASTM C128-12 [54] \\
Soundness (>0.3 mm particle) & $\%$ & $\leq 12$ & 6.0 & ASTM C88/C88M-18 [50] \\
Sand equivalent & $\%$ & $\geq 65$ & 71 & ASTM D2419-14 [55] \\
\hline
\end{tabular}

\subsection{Gradation Design}

HCUP puts forward higher functional performance and durability requirements relative to the micro-surface, so the dense skeleton structure is used as the grading design goal to obtain a cold-laid surface with high skeleton strength, good water tightness, and strong wear resistance. At the same time, to reduce the interference between the aggregates, it is proposed to increase the amount of bitumen to replace part of the fine aggregates to strengthen the framework of the mixture and bonding performance between the frameworks. The specific mixture design procedure are as follows:

(1) The voids of coarse aggregate in the dry rodded condition $\left(V C A_{D R C}\right)$ are measured, and the amount of bitumen, mineral powder and the designed volume of air voids $\left(V_{V}\right)$ are preliminarily determined based on the engineering practice experience. (Generally, the ratio of bitumen to aggregate is above $10 \%$; the amount of mineral powder is $2 \%$ to $4 \%$ of the mineral aggregate, and the VV is controlled at $3 \%$ to $6 \%$ ).

(2) The coarse aggregate voids filling method (CAVF) is used to calculate the proportion of coarse and fine aggregates and combine the gradation range (Table 5) to synthesize the gradation curve. The calculation process satisfies Equations (1) and (2):

$$
\begin{gathered}
q_{c}+q_{f}+q_{p}=100 \% \\
\frac{q_{c}}{100 \gamma_{s}}\left(V C A-V_{V}\right)=\frac{q_{f}}{\gamma_{f}}+\frac{q_{p}}{\gamma_{p}}+\frac{q_{a}}{\gamma_{a}},
\end{gathered}
$$


where $q_{c}, q_{f}$, and $q_{p}$ are the mass percentages of coarse aggregate, fine aggregate, and mineral powder, $\% ; q_{a}$ is the ratio of bitumen to aggregate, $\% ; \gamma_{f}$, and $\gamma_{p}$ are the apparent relative density of fine aggregate and mineral powder, respectively; $\gamma_{a}$ is the relative density of bitumen; and $\gamma_{s}$ is the compact density of coarse aggregate.

Table 5. Gradation of HCUP-8 mixture.

\begin{tabular}{cccccccccc}
\hline \multirow{2}{*}{ HCUP-8 } & \multicolumn{10}{c}{ Mass Percentage (\%) } & through & the Control Sieve (mm) \\
& $\mathbf{9 . 5}$ & $\mathbf{7 . 2}$ & $\mathbf{4 . 7 5}$ & $\mathbf{2 . 3 6}$ & $\mathbf{1 . 1 8}$ & $\mathbf{0 . 6}$ & $\mathbf{0 . 3}$ & $\mathbf{0 . 1 5}$ & $\mathbf{0 . 0 7 5}$ \\
\hline Upper limit & 100 & 100 & 80 & 35 & 25 & 20 & 15 & 12 & 8 \\
Lower limit & 100 & 85 & 30 & 15 & 8 & 6 & 5 & 4 & 3 \\
\hline
\end{tabular}

(3) Prepare the Marshall specimens according to the synthetic gradation to verify whether Equations (3) and (4) are established. If the above two conditions cannot meet the design requirements at the same time, the gradation design should be re-designed. If the above two conditions meet the design requirements, an attempt can be made to reduce the bitumen-aggregate ratio from an economic point of view. The technical requirements of the HCUP-8 mixture are shown in Table 6.

$$
\begin{gathered}
V C A_{\text {mix }} \leq V C A_{D R C}, \\
D A \geq 16 \mathrm{um},
\end{gathered}
$$

where $V C A_{\text {mix }}$ is the void of the coarse aggregate in the mixture, $\%$, and $D A$ is the depth of the bitumen, um.

Table 6. Technical requirements of HCUP-8 mixture.

\begin{tabular}{cccc}
\hline Properties & Units & $\begin{array}{c}\text { Technical } \\
\text { Requirement }\end{array}$ & Test Method \\
\hline Bitumen content (bitumen & $\%$ & $\geq 10.0$ & ASTM D6307-19 [56] \\
aggregate ratio) & $\%$ & $\geq 85.0$ & ASTM D5581-07A(2013) [57] \\
Retained Marshall stability & $\%$ & $\geq 80.0$ & AASHTO T283 [58] \\
Tensile strength ratio & cycles $/ \mathrm{mm}$ & $\geq 5000$ & ASTM D8292-20 [59] \\
Dynamic stability & $\%$ & $\leq 10.0$ & ASTM D7064/D7064M-21 [60] \\
Scattering loss & $\mathrm{mm}$ & $\geq 0.8$ & ASTM E965 [61] \\
Texture depth & & & \\
\hline
\end{tabular}

\section{Road Performance Evaluation Method}

\subsection{Contrast Experimental Group}

In order to better evaluate the road performance of HCUP-8, three different types of hot mix asphalt mixtures, including AC-10, Novachip, and GT-8, were used as the comparative experimental group. The thickness of AC-10 is generally $3 \mathrm{~cm}$, and it is usually used as the surface wear layer of roads with lower traffic volume. The thickness of Novachip is usually $2-2.5 \mathrm{~cm}$, and it is one of the first ultra-thin wear layer technologies proposed and widely used in high-grade highways in the United States. The thickness of GT-8 is usually $0.8-2.0 \mathrm{~cm}$, which is a new type of ultra-thin wear layer technology, which is widely used in China and produces good economic benefits.

AC-10 and Novachip use SBS modified bitumen (PG76-22) as a binder. The technical requirements for bitumen are shown in Table 7 . The high-viscosity and high-elastic bitumen used in GT- 8 is the main raw material for preparing HCUP emulsified bitumen, and its technical indicators meet the requirements of Table 1 . The grading curve of AC-10, Novachip, HCUP-8 and GT-8 is shown in Figure 1. 
Table 7. Technical index of the SBS modified bitumen (PG76-22).

\begin{tabular}{ccccc}
\hline Properties & Units & $\begin{array}{c}\text { Technical } \\
\text { Requirement }\end{array}$ & Test Results & Test Method \\
\hline Penetration $\left(25^{\circ} \mathrm{C}, 5 \mathrm{~s}, 100 \mathrm{~g}\right)$ & $0.1 \mathrm{~mm}$ & $40 \sim 60$ & 50 & ASTM D5-06E1 [35] \\
Softening point & ${ }^{\circ} \mathrm{C}$ & $\geq 70$ & 81 & ASTM D36-06 [36] \\
Elastic recovery $\left(25^{\circ} \mathrm{C}\right)$ & $\%$ & $\geq 85$ & 97 & ASTM D6084/D6084M-21 [37] \\
Solubility (Trichloroethylene) & $\%$ & $\geq 99$ & 99.5 & ASTM D2042-01 [38] \\
Storage stability & \multicolumn{1}{c}{$\mathrm{C}$} & $\leq 1$ & 0.9 & ASTM D5-06E1976 [39] \\
Dynamic viscosity at $60^{\circ} \mathrm{C}$ & $\mathrm{Pa} \cdot \mathrm{s}$ & $\geq 800$ & 1836 & ASTM D2171-07E1 [41] \\
After short-term aging & $\%$ & \pm 1.0 & -0.01 & ASTM D2872-04 [42] \\
Mass loss & $\%$ & $\geq 65$ & 77.0 & ASTM D5-06E1 [35] \\
Penetration ratio $\left(25^{\circ} \mathrm{C}\right)$ & ${ }^{\circ} \mathrm{C}$ & $\geq 76$ & 76 & ASTM D7175-15 [43] \\
\hline $\mathrm{G}^{*} / \sin \delta=2.2 \mathrm{kPa}$ critical temperature & &
\end{tabular}

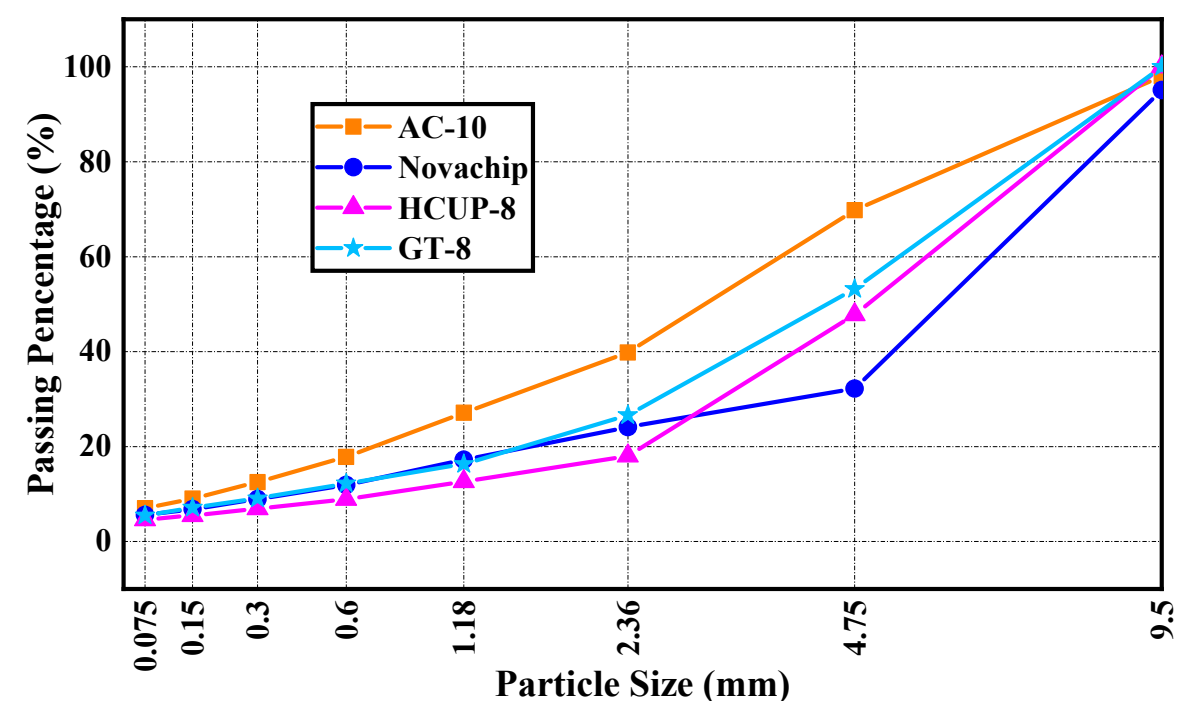

Figure 1. Grading curve of AC-10, Novachip, HCUP-8 and GT-8.

\subsection{Testing Program}

Fatigue damage and the cracking of asphalt pavement are currently the most difficult to prevent and treat. They are mainly caused by the combined action of vehicle load, environmental factors, and temperature factors. Due to the thinner thickness of the ultra-thin wear layer, it is more prone to cracking than the traditional 4-5 cm wear layer. Therefore, in addition to conventional road performance tests, this article uses the low-temperature bending test, impact toughness test, semicircular bend test (SCB), and four-point beam fatigue test to evaluate and analyze the crack resistance of HCUP.

\subsubsection{Standardized Performance Tests}

Supervised by the ASTM D5581-07A(2013) and AASHTO T283 [57,58], the retained Marshall stability test and tensile strength test were carried out, respectively. The former evaluates the water damage resistance of the bitumen binder, while the latter evaluates the water stability of the asphalt mixture in areas with high temperature differences, especially in frozen areas.

Under the guidance of JTG T0719 and JTG T0733 [45], the dynamic stability test and Scattering loss test of asphalt mixture were carried out, respectively. The former is used to evaluate the high temperature stability of the asphalt mixture, and the latter is usually used to evaluate the degree of aggregate peeling from the road surface. At the same time, the texture depth test of the mixture was carried out with reference to ASTM E965 to evaluate its anti-skid performance [61]. Part of the standard performance test is shown in Figure 2. 


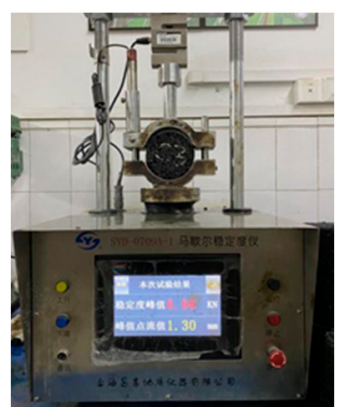

(a)

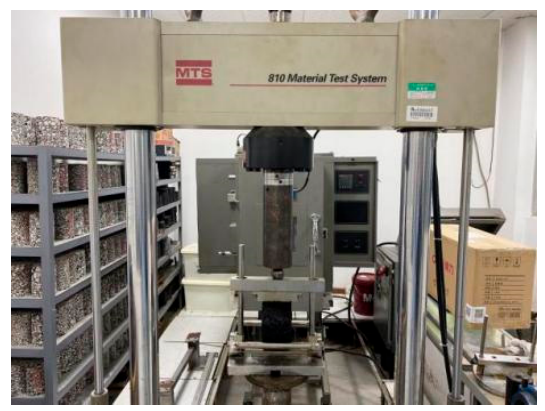

(b)

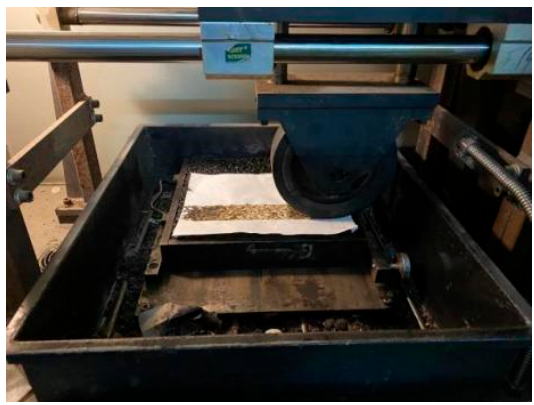

(c)

Figure 2. Standardized performance tests: (a) Marshall stability test; (b) tensile strength test; (c) dynamic stability test.

\subsubsection{Crack Resistance Test}

The low temperature bending test of asphalt mixtures was conducted using a Nottingham Asphalt Tester (NAT-10, developed by University of Nottingham, Nottingham, U.K., Figure 3a), according to ASTM C293/C293M-16 [62]. The tests were performed at $-10 \pm$ $0.5{ }^{\circ} \mathrm{C}$. The loading rate is $50 \mathrm{~mm} / \mathrm{min}$. A concentrated load is applied to the center of the specimen at a prescribed rate until the specimen is broken, then the breaking load and mid-span deflection are measured to calculate the flexural tensile strength and ultimate flexural tensile strain.

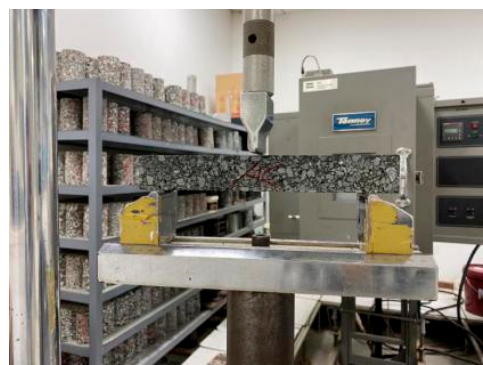

(a)

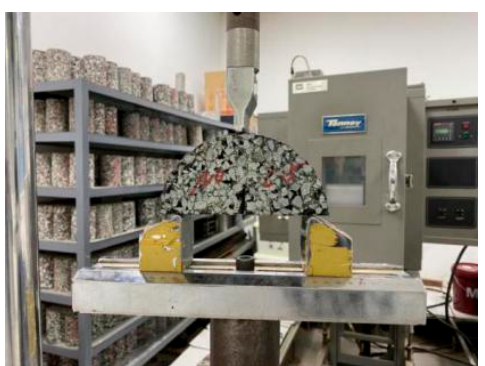

(b)

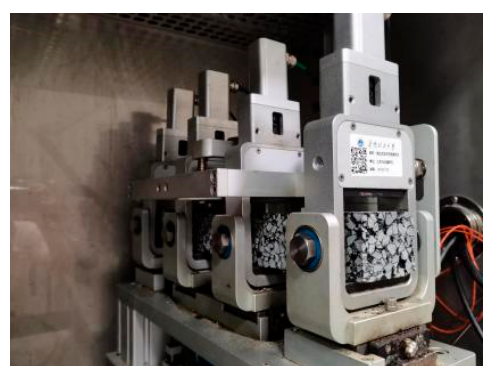

(c)

Figure 3. Anti-cracking performance tests: (a) low temperature bending test and impact toughness test; (b) semicircular bend test (SCB); (c) four-point beam fatigue test.

The impact toughness test is based on the low temperature bending test. The loading rate and test temperature of low temperature bending test were changed to a load rate of $500 \mathrm{~mm} / \mathrm{min}$ and test temperature of $15^{\circ} \mathrm{C}$ to conduct the impact toughness test. This test method was first proposed by Professor Zhang Xiaoning to simulate the impact of wheels on the road surface [63]. The impact toughness test uses the area from the point of load application to the maximum load point in the load-displacement curve to characterize the energy required for the asphalt mixture to break due to the impact load, and to evaluate the ability of the asphalt mixture to resist the impact load. Correlative tests verified a good correlation between the impact toughness and fatigue life of the asphalt mixture.

The semicircular bend test (SCB) of asphalt mixtures was conducted using a Nottingham Asphalt Tester (NAT-10, developed by University of Nottingham, Nottingham, U.K., Figure 3a), according to ASTM D8044-16 [64]. The tests were performed at $15 \pm 0.5^{\circ} \mathrm{C}$. The loading rate is $50 \mathrm{~mm} / \mathrm{min}$. A concentrated load was applied to the cut section of the specimen until the specimen fractures. The maximum load work and fracture energy were calculated by measuring the fracture load and vertical displacement of the specimen with different notch depths.

The four-point beam fatigue test of asphalt mixtures was conducted using a Cooper NU-14 tester (Cooper Research Technology-Technical Centre, Ripley, Derbyshire, U.K.), according to ASTM D8237-21 [65]. The tests were performed at $15 \pm 0.5^{\circ} \mathrm{C}$. A strain level 
of 1000 microstrains and a loading frequency of $10 \mathrm{~Hz}$ were used. During each load cycle beam, deflections were measured at the center of the beam to calculate the maximum tensile stress, maximum tensile strain, phase angle, stiffness, dissipated energy, and cumulative dissipated energy. Failure is assumed to occur when the stiffness has reached half of its initial value, which is determined from the load at approximately 50 repetitions; the test is terminated automatically when this load has diminished by $50 \%$.

\section{Results and Discussion}

\subsection{Standardized Performance Tests}

From Figure 4 and Table 8, it can be concluded that the retained Marshall stability ratio of all asphalt mixtures has a relatively high level, and the stability strength is ranked as AC-10, Novachip, GT-8, and HCUP-8 in order. It is worth noting that the Marshall stability of HCUP-8 is $6.86 \mathrm{kN}$, which exceeds the technical requirements of ordinary hot mix asphalt mixtures.

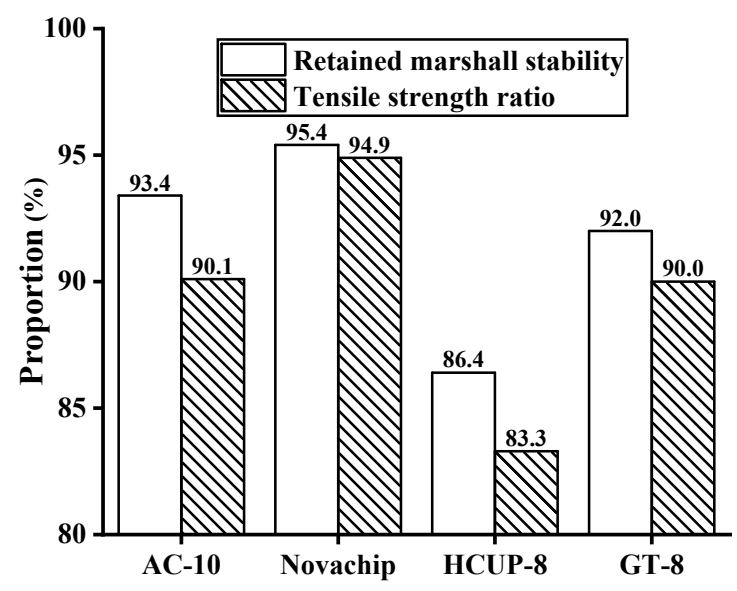

Figure 4. Results of Marshall stability and tensile strength.

Table 8. Marshall stability test results.

\begin{tabular}{cccc}
\hline \multirow{2}{*}{ Mixture Type } & \multicolumn{2}{c}{ Marshall Stability (kN) } & \multirow{2}{*}{ Retained Marshall Stability (\%) } \\
& $\mathbf{6 0}{ }^{\circ} \mathbf{C}, \mathbf{0 . 5} \mathbf{~ h}$ & $\mathbf{6 0}{ }^{\circ} \mathbf{C}, \mathbf{4 8} \mathbf{~ h}$ & 93.4 \\
AC-10 & $12.72 \pm 0.31$ & $11.88 \pm 0.81$ & 95.4 \\
Novachip & $9.53 \pm 1.09$ & $9.09 \pm 0.40$ & 86.4 \\
HCUP-8 & $6.86 \pm 0.56$ & $5.93 \pm 0.93$ & 92.0 \\
GT-8 & $9.50 \pm 0.42$ & $8.74 \pm 0.40$ & \\
\hline
\end{tabular}

Figure 4 and Table 9 show the tensile strength of the asphalt mixture before and after freeze-thaw. The results of the non-freeze-thaw group show that the tensile strength of HCUP-8 and the traditional hot mix ultra-thin wear layer is almost at the same level. However, after freezing and thawing, the tensile strength of HCUP-8 attenuates greatly, and its tensile strength ratio is only $83.3 \%$. From the perspective of resistance to water damage, HCUP-8 is more suitable for temperate or tropical regions compared to frozen regions.

Table 10 and Figure 5 show the dynamic stability, scattering loss and texture depth of different asphalt mixtures. It can be seen that the dynamic stability of HCUP-8 is much higher than that of AC-10 and Novachip, indicating that HCUP-8 has better hightemperature rutting resistance. In terms of spalling loss and structural depth, the performance of all asphalt mixtures is in the same order, which is Novachip, HCUP-8, GT-8 and AC-10 in descending order. 
Table 9. Tensile strength test results.

\begin{tabular}{cccccc}
\hline \multirow{2}{*}{ Mixture Type } & \multicolumn{2}{c}{$\begin{array}{c}\text { Unfreeze-Thaw Group } \\
\text { Critical Load (kN) }\end{array}$} & $\begin{array}{c}\text { Tensile Strength (MPa) } \\
\text { Critical Load (kN) }\end{array}$ & $\begin{array}{c}\text { Freeze-Thaw Group } \\
\text { Tensile Strength (MPa) }\end{array}$ & $\begin{array}{c}\text { Tensile Strength } \\
\text { Ratio (\%) }\end{array}$ \\
\hline AC-10 & $11.06 \pm 0.53$ & $1.11 \pm 0.06$ & $10.13 \pm 0.30$ & $1.00 \pm 0.03$ & \\
Novachip & $9.84 \pm 0.55$ & $0.98 \pm 0.06$ & $9.36 \pm 0.35$ & $0.93 \pm 0.03$ & 9.1 \\
HCUP-8 & $7.25 \pm 0.28$ & $0.72 \pm 0.03$ & $6.10 \pm 0.37$ & $0.60 \pm 0.03$ & 83 \\
GT-8 & $8.81 \pm 0.35$ & $0.87 \pm 0.03$ & $7.85 \pm 0.32$ & $0.78 \pm 0.03$ & 90.3 \\
\hline
\end{tabular}

Table 10. Results of dynamic stability, scattering loss and texture depth.

\begin{tabular}{cccc}
\hline Mixture Type & $\begin{array}{c}\text { Dynamic Stability } \\
\text { (Cycles/mm) }\end{array}$ & Scattering Loss (\%) & Texture Depth (mm) \\
\hline AC-10 & $7922 \pm 608$ & $4.9 \pm 0.82$ & $0.93 \pm 0.04$ \\
Novachip & $7865 \pm 1659$ & $6.4 \pm 0.28$ & $1.31 \pm 0.04$ \\
HCUP-8 & $8573 \pm 370$ & $6.0 \pm 0.53$ & $0.95 \pm 0.03$ \\
GT-8 & $10,151 \pm 478$ & $5.2 \pm 0.43$ & $0.97 \pm 0.04$ \\
\hline
\end{tabular}

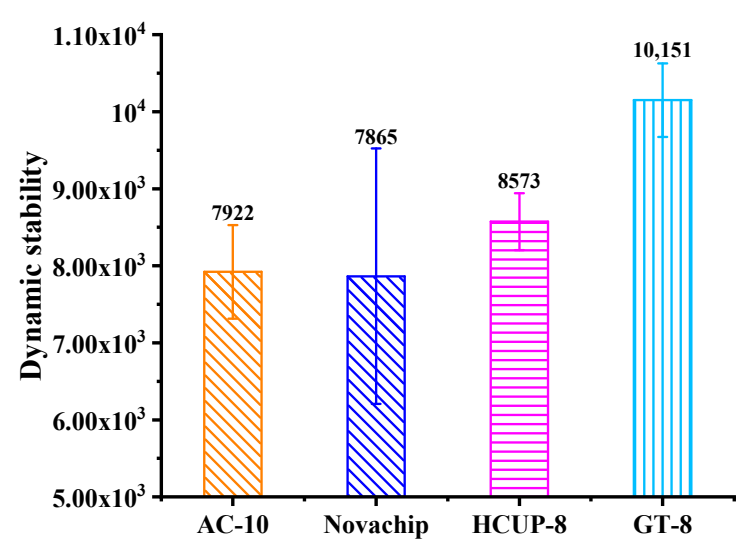

(a)

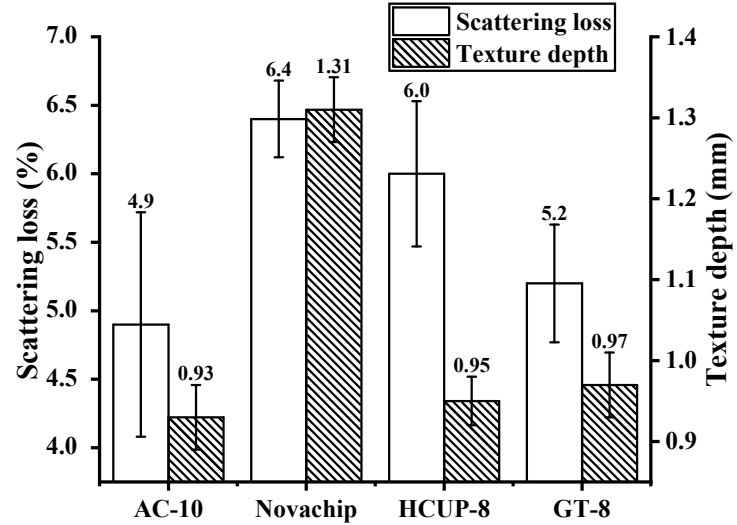

(b)

Figure 5. (a) Dynamic stability test; (b) scattering loss test and texture depth test.

The three indexes of dynamic stability, scattering loss and texture depth are highly correlated with the structure of the asphalt mixture. Novachip has a skeleton void structure, so it has high texture depth but poor peeling resistance. AC-10 is a suspended compact structure, so it has good peeling resistance but weak texture depth and high temperature performance. Both HCUP-8 and GT- 8 have a dense skeleton structure, which has good high temperature performance and anti-stripping performance. At the same time, the special skeleton design makes its texture depth at the same level as AC-10.

\subsection{Crack Resistance Test}

\subsubsection{Low Temperature Bending Test}

The typical load-displacement curves of AC-10, NOVACHIP, HCUP-8 and GT-8 mixtures are shown in Figure 6. The NOVACHIP and AC-10 specimens experienced brittle failure in a small area before reaching the maximum load, which affected the final value of the strength of the specimen. The overall brittle fracture occurred after reaching the maximum failure load, and the specimen quickly lost overall strength. The HCUP and GT-8 specimens are in plastic failure after reaching the maximum failure load, and still retains a certain degree of toughness at this time.

It can be seen from Table 11 that the ultimate bending strain of HCUP and GT- 8 is much higher than that of NOVACHIP and AC-10, which are 4527.2 $\mu \varepsilon$ and $5611.7 \mu \varepsilon$, respectively, which proves that the crack resistance of HCUP and GT-8 in low temperature environment is better than that of the conventional ultra-thin wear layer. In addition, from 
the point of view of flexural tensile strength, the mechanical properties of HCUP also surpass the ordinary ultra-thin friction layer, and it has better crack resistance.

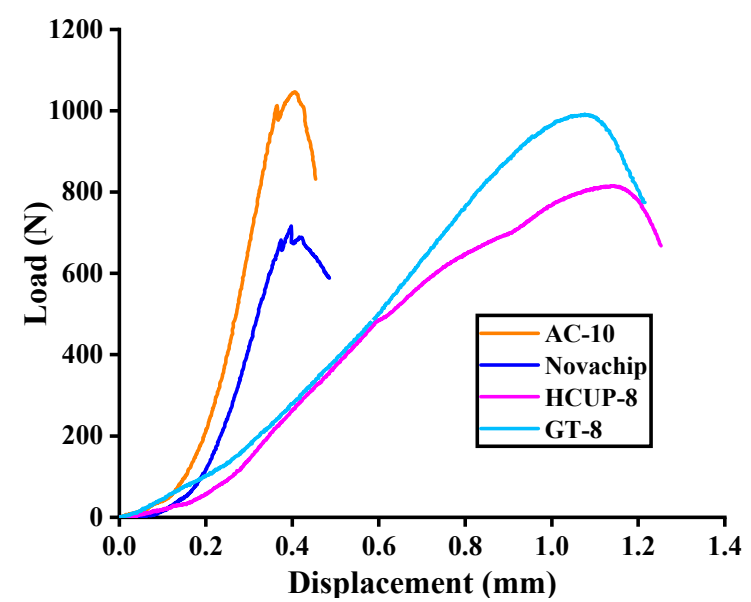

Figure 6. Load-displacement curve of low temperature bending test.

Table 11. Results of low temperature bending test.

\begin{tabular}{ccccc}
\hline Mixture Type & Critical Load (N) & Mid-Span Deflection (mm) & $\begin{array}{c}\text { Flexural Tensile } \\
\text { Strength }(\mathbf{M P a})\end{array}$ & $\begin{array}{c}\text { Ultimate Flexural } \\
\text { Strain }(\boldsymbol{\mu \varepsilon})\end{array}$ \\
\hline AC-10 & $1077.168 \pm 26.462$ & $0.261 \pm 0.003$ & $8.793 \pm 0.249$ & $1367.612 \pm 17.737$ \\
NOVACHIP & $735.323 \pm 22.377$ & $0.225 \pm 0.010$ & $6.003 \pm 0.211$ & $1183.193 \pm 62.144$ \\
HCUP-8 & $807.963 \pm 42.322$ & $0.862 \pm 0.054$ & $6.596 \pm 0.399$ & $4527.193 \pm 329.673$ \\
GT-8 & $1006.675 \pm 40.371$ & $1.069 \pm 0.052$ & $6.605 \pm 0.403$ & $5611.721 \pm 329.785$ \\
\hline
\end{tabular}

\subsubsection{Impact Toughness Test}

The typical load-displacement curves of AC-10, NOVACHIP, HCUP-8 and GT-8 mixtures are shown in Figure 7. HCUP-8 and GT-8 specimens remains relatively "constant" in a large vertical deformation displacement area close to the critical load, indicating that they have better resistance to deformation when responding to impact loads. However, the displacement of the NOVACHIP and AC-10 asphalt mixture specimens changes drastically when the critical load approaches, indicating that brittle fracture is prone to occur when resisting the impact load. According to Table 12, the impact toughness relationship of the four asphalt mixture specimens is GT- $8>$ HCUP-8 $>$ AC-10 > NOVACHIP, which proves that HCUP has superior crack resistance when subjected to impact loads.

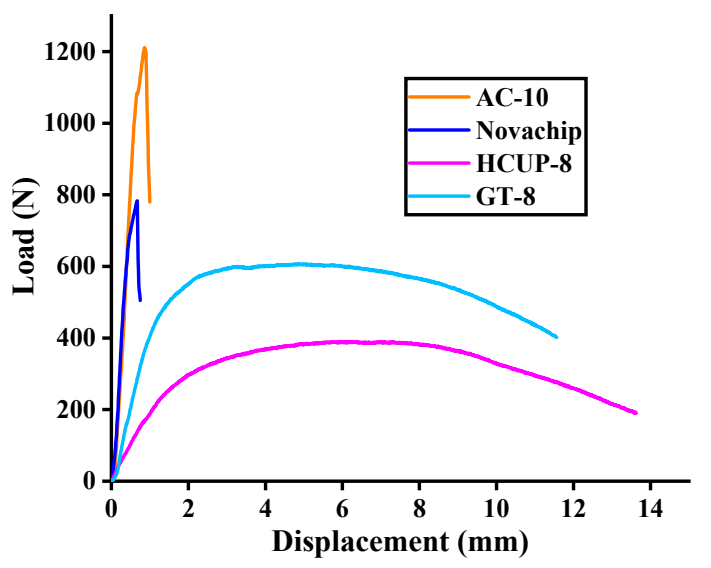

(a)

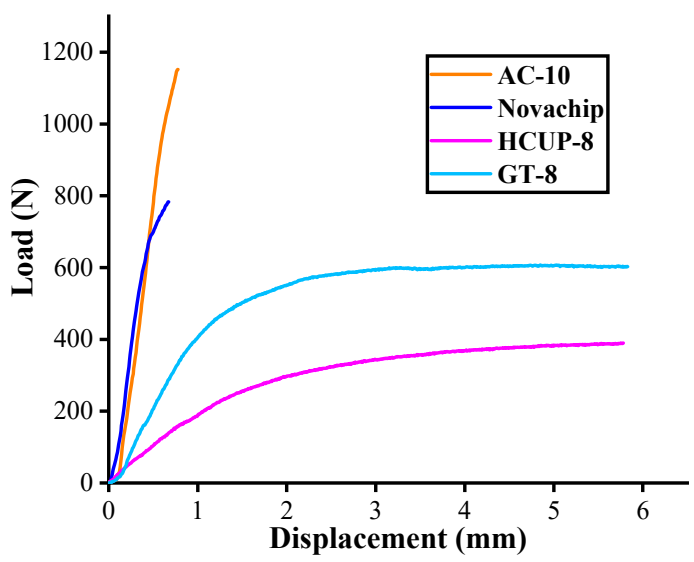

(b)

Figure 7. Load-displacement curve of impact toughness test: (a) load-displacement curve; (b) calculation diagram of impact toughness curve. 
Table 12. Results of impact toughness test.

\begin{tabular}{cccc}
\hline Mixture Type & Critical Load (N) & $\begin{array}{c}\text { Critical } \\
\text { Displacement (mm) }\end{array}$ & $\begin{array}{c}\text { Impact Toughness } \\
\mathbf{( N \cdot m m )}\end{array}$ \\
\hline NOVACHIP & $805.318 \pm 39.784$ & $0.693 \pm 0.042$ & $325.300 \pm 41.249$ \\
AC-10 & $1189.125 \pm 23.229$ & $0.790 \pm 0.043$ & $487.575 \pm 44.886$ \\
HCUP-8 & $327.325 \pm 36.836$ & $5.709 \pm 0.149$ & $1471.825 \pm 140.585$ \\
GT-8 & $606.175 \pm 7.859$ & $5.887 \pm 0.210$ & $2828.650 \pm 200.260$ \\
\hline
\end{tabular}

\subsubsection{Semicircular Bend test}

The typical load-displacement curves of AC-10, NOVACHIP, HCUP-8 and GT-8 mixtures are shown in Figure 8. With the increase in the notch depth, the maximum load of the four asphalt mixtures is relatively smaller because the notch depth will affect the size of the cross section of the specimen to withstand the internal tensile stress, which proves that the test results conform to the design principle of the semicircular bending test. On the other hand, within the $5 \%$ load range of the specimen before and after the failure load, the vertical deformation displacement of the AC-10, NOVACHIP, HCUP-8 and GT-8 asphalt mixture specimens with a cut of $1.5 \mathrm{~cm}$ is $0.77 \mathrm{~mm}, 0.60 \mathrm{~mm}, 1.13 \mathrm{~mm}$ and $1.20 \mathrm{~mm}$. The vertical deformation displacements of the AC-10, NOVACHIP, HCUP-8 and GT-8 asphalt mixture specimens with a cut of $2.5 \mathrm{~cm}$ is $0.50 \mathrm{~mm}, 0.42 \mathrm{~mm}, 1.61 \mathrm{~mm}$ and $0.7 \mathrm{~mm}$. It can be seen that under high load conditions, the anti-deformation abilities of the HCUP-8 and GT- 8 asphalt mixtures are better than those of the other two asphalt mixtures. At the same time, as the notch depth increases, the vertical deformation displacement of AC-10, NOVACHIP and GT-8 is relatively smaller, reflecting the nature of brittle materials, that is, the smaller the cross-sectional area subjected to tensile stress, the easier it is to break. The vertical deformation displacement of HCUP-8 increases with the increase in the notch depth, that is, in the case of high load, the smaller the HCUP-loaded area and the stronger the deformation resistance, which reflects the characteristics of ductile materials.

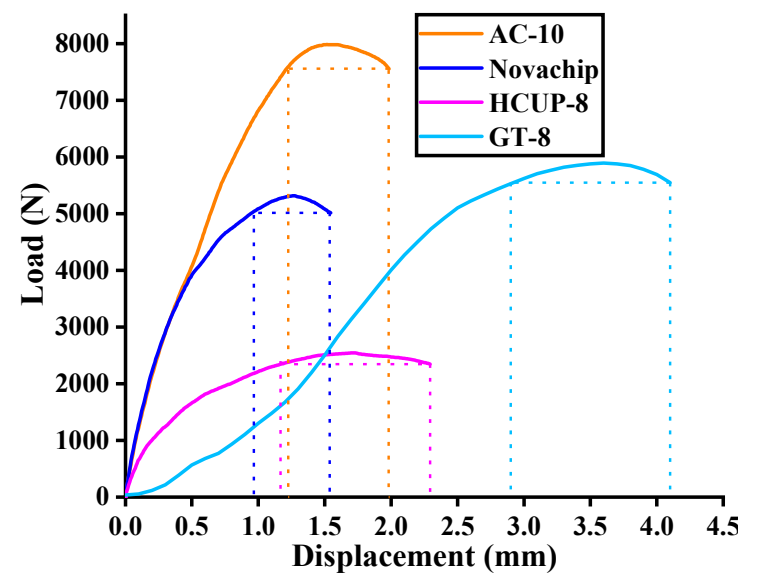

(a)

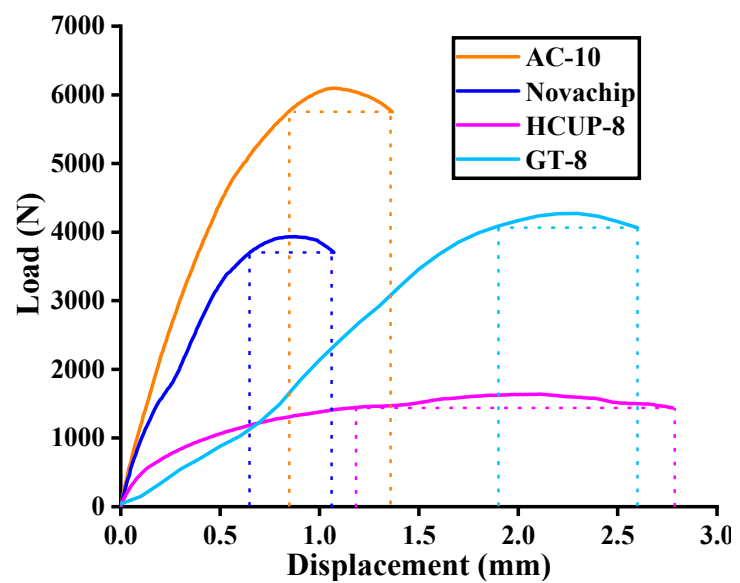

(b)

Figure 8. Load-displacement curve of semicircle bending test: (a) the notch depth is $15 \mathrm{~mm}$; (b) the notch depth is $25 \mathrm{~mm}$.

Figure 9 shows the calculation curve range of the maximum load for the semicircular bending test. The integral area enclosed by the load-displacement curve from the beginning of the applied load to the critical load is the load work when the semicircular specimen fails. The fracture energy of asphalt mixture can be calculated by the maximum load work of semicircular specimens with different notch depths. The related calculation results are shown in Table 13. The fracture energies of the AC-10, NOVACHIP, HCUP-8 and GT-8 asphalt mixture samples were calculated to be $3.286 \mathrm{~kJ} / \mathrm{m}^{2}, 4.814 \mathrm{~kJ} / \mathrm{m}^{2}, 5.079 \mathrm{~kJ} / \mathrm{m}^{2}$ and $11.165 \mathrm{~kJ} / \mathrm{m}^{2}$, respectively. Among them, GT-8 has the largest fracture energy, followed by 
HCUP-8, which proves that HCUP-8 has better deformation resistance than AC-10 and Novachip.

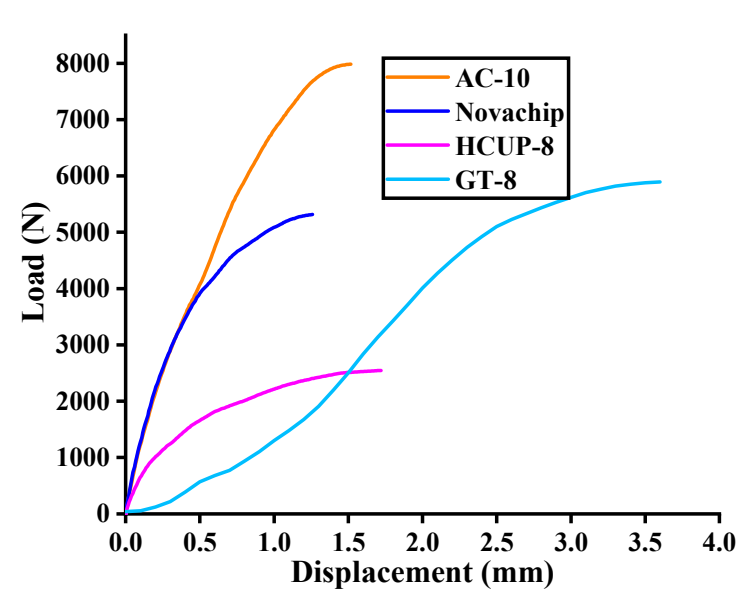

(a)

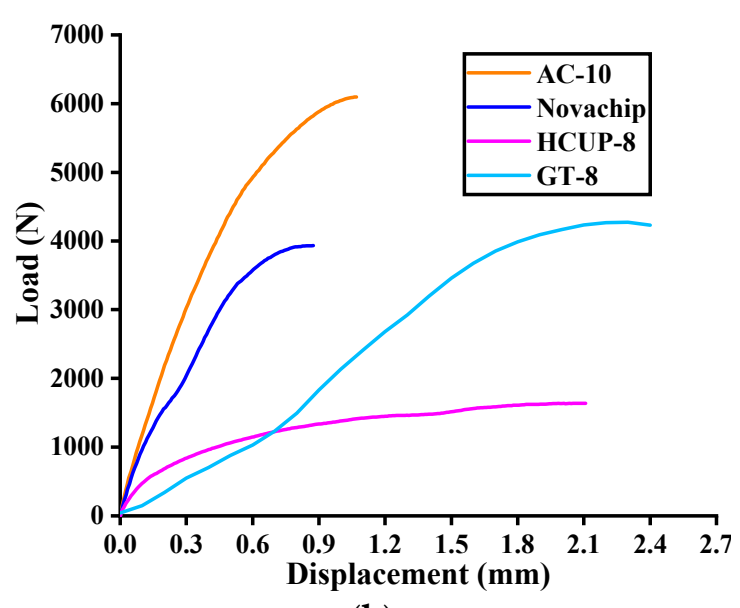

(b)

Figure 9. Load work calculation curve for semicircular bending test: (a) the notch depth is $15 \mathrm{~mm}$; (b) the notch depth is $25 \mathrm{~mm}$

Table 13. Results of semicircular bend test.

\begin{tabular}{cccc}
\hline Mixture Type & Notch Depth $(\mathbf{m m})$ & Maximum Load Work $(\mathbf{J})$ & Fracture Energy $\mathbf{( k J / \mathbf { m } ^ { 2 } )}$ \\
\hline \multirow{2}{*}{ AC-10 } & 15 & $7.227 \pm 0.449$ & 4.814 \\
& 25 & $4.818 \pm 0.413$ & \\
Novachip & 15 & $4.108 \pm 0.397$ & 3.286 \\
& 25 & $2.465 \pm 0.121$ & 5.079 \\
HCUP-8 & 15 & $3.190 \pm 0.240$ & \\
& 25 & $0.651 \pm 0.059$ & 11.165 \\
GT-8 & 15 & $11.532 \pm 0.539$ & \\
\end{tabular}

\subsubsection{Four-Point Beam Fatigue Test}

It can be seen from Table 14 that, at a strain level of $1000 \mu \varepsilon$, the fatigue life of various asphalt mixtures in descending order is GT-8 > HCUP-8 $>$ SMA-10 > AC-10 > Novachip. It is worth noting that the fatigue life of HCUP-8 has reached 224,671 times, far exceeding those of traditional hot-mixed ultra-thin wear layer materials, such as AC-10, Novachip, and SMA-10. Generally, the four-point bending fatigue test with a strain level of $1000 \mu \varepsilon$ is only used to evaluate the crack resistance of the stress-absorbing layer-grade asphalt mixture. This test further verified that the HCUP-8 has excellent crack resistance under repeated bending loads with high strain levels. The reasons behind it are the high PG grade asphalt binder, high oil film thickness, and the design concept of using high asphalt content to replace part of the fine aggregate, which makes the HCUP-8 material tougher.

Table 14. Results of four point bending fatigue test.

\begin{tabular}{cc}
\hline Mixture Type & Cycles of Failure $(\boldsymbol{\mu} \varepsilon=\mathbf{1 0 0 0})$ \\
\hline AC-10 & $5367 \pm 910$ \\
Novachip & $3833 \pm 791$ \\
HCUP-8 & $224,671 \pm 35,428$ \\
GT-8 & $925,903 \pm 198,200$ \\
SMA-10 & $11,201 \pm 1736$ \\
\hline
\end{tabular}




\section{Application of HCUP}

\subsection{Test Road Construction}

In order to further verify the road performance of HCUP, a test road was paved on China's G78 highway, with a length of $122 \mathrm{~m}$ and a width of $3.75 \mathrm{~m}$. The construction steps and engineering effects are shown in Figure 10.

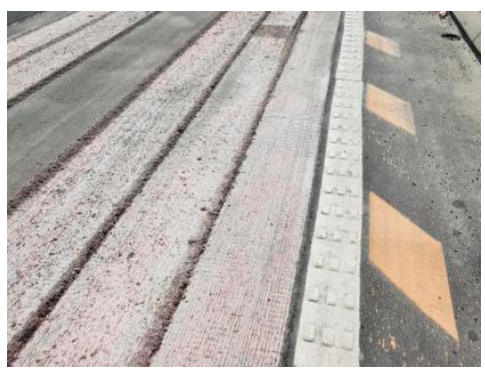

(a)

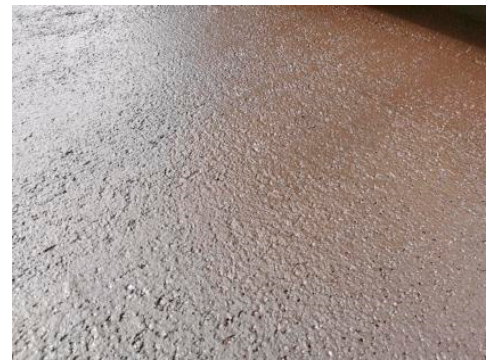

(d)

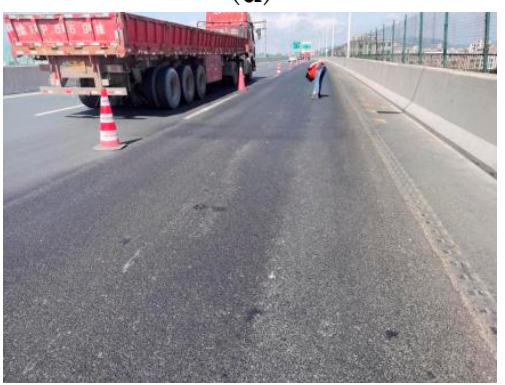

$(\mathrm{g})$

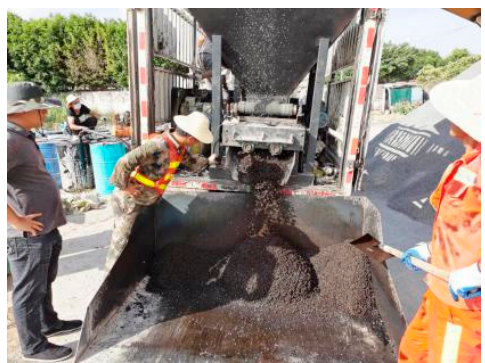

(b)

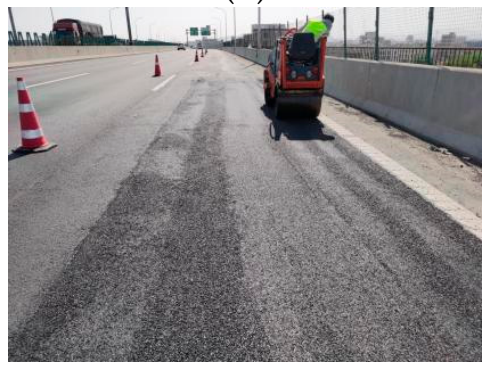

(e)

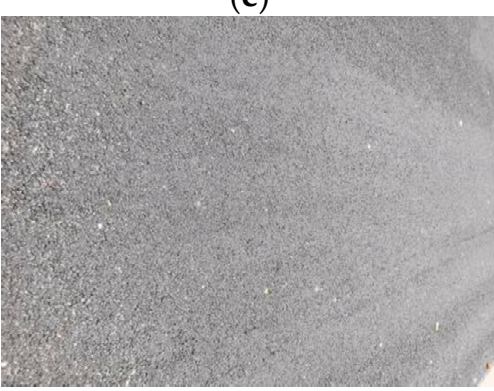

(h)

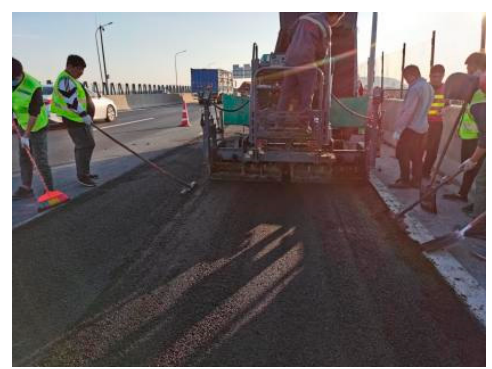

(c)

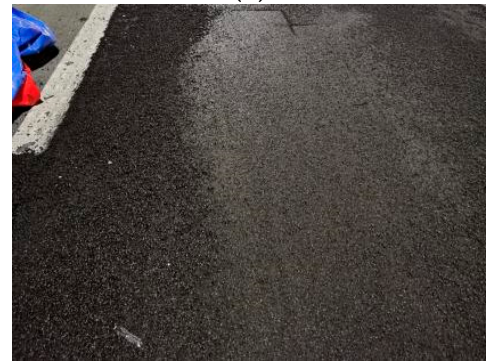

$(\mathbf{f})$

Figure 10. Application of HCUP: (a) original pavement milling; (b) mixture production; (c) paving construction; (d) paving surface details; (e) roller construction; (f) rolled surface details; (g) pavement after six months; (h) pavement details after six months.

\subsection{Test Road Detection}

Test the friction coefficient, texture depth, water seepage coefficient, and tensile strength of HCUP-8 pavement, evaluate its true performance, and propose engineering quality acceptance standards. HCUP-8 performance test data and quality acceptance requirements are shown in Table 15.

Table 15. HCUP-8 quality acceptance requirements and test results.

\begin{tabular}{ccccc}
\hline Properties & Units & $\begin{array}{c}\text { Technical } \\
\text { Requirement }\end{array}$ & Test Results & Test Method \\
\hline Friction & $\mathrm{BPN}$ & $\geq 55$ & $75.1 \pm 0.8$ & ASTM E303 [66] \\
coefficient & $\mathrm{mm}$ & $\geq 0.8$ & $1.3 \pm 0.2$ & ASTM E965 [61] \\
Texture depth & $\leq 80$ & $20 \pm 7$ & JTG T0971 [67] \\
Water seepage & $\mathrm{ml} / \mathrm{min}$ & $\geq 0.3$ & $0.48 \pm 0.06$ & ASTM D4541 [68] \\
coefficient & $\mathrm{MPa}$ & & & \\
Tensile strength & & &
\end{tabular}


Table 15 proves that HCUP-8 has excellent road performance. Specifically, the texture depth is $1.3 \mathrm{~mm}$, the friction coefficient is $75.1 \mathrm{BPN}$, the water permeability coefficient is $20 \mathrm{~mL} / \mathrm{min}$, and the tensile strength is $0.48 \mathrm{MPa}$. The field test data of the test road laid the foundation for the promotion of HCUP-8.

\section{Conclusions}

This research proposes a "high toughness cold mix ultra-thin pavement (HCUP)" technology with a thickness of $0.8-2.0 \mathrm{~cm}$ and introduces the key elements of material design and grading design.

Conventional road performance tests show that the strength of HCUP-8 meets the design requirements of ordinary hot mix asphalt mixtures, and it has high temperature performance and anti-skid performance, superior to traditional hot mix ultra-thin wear layers. However, its water stability is poor but still meets industry requirements.

The anti-cracking test shows that although the deformation resistance of HCUP is not as good as GT-8, it is far superior to traditional hot mix asphalt concrete technologies, such as AC-10 and Novachip, especially when dealing with impact loads. It is worth noting that the large-strain four-point bending fatigue test proved that HCUP has the crack resistance of the stress-absorbing layer. This is related to the design of high-asphalt film thickness and the concept of using high-asphalt content to replace part of the fine aggregate.

The field test results of the test road further verified the excellent performance of HCUP-8. Future research will focus on the long-term road performance tracking of HCUP-8.

Author Contributions: Data curation, N.Y.; funding acquisition, J.Y.; investigation, N.Y., F.C., J.Y., Y.C. and H.Y.; methodology, J.Y., H.Y., N.Y., Y.C., Z.L. and F.C.; supervision, J.Y.; writing-original draft, N.Y.; writing-review and editing, H.Y. All authors have read and agreed to the published version of the manuscript.

Funding: This research was funded by National Natural Science Foundation of China (52178426, 51808228), Science and Technology Program of Guangzhou (202102020439), and the Open Fund of National Engineering Laboratory of Highway Maintenance Technology (KFJ190106, Changsha University of Science \& Technology).

Institutional Review Board Statement: Not applicable.

Informed Consent Statement: Not applicable.

Data Availability Statement: The data presented in this study are available on request from the corresponding author.

Acknowledgments: The authors would like to thank the technicians in the Road laboratories of South China University of Technology, Shaohuai Wang, Guanwen Jiang, for their technical support and assistance in experimental activities.

Conflicts of Interest: The funders had no role in the design of the study; in the collection, analyses, or interpretation of data; in the writing of the manuscript, or in the decision to publish the results.

\section{References}

1. Chan, S.; Lane, B.; Kazmierowski, T. Pavement preservation: A solution for sustainability. Transp. Res. Rec. 2011, 47, 36-42. [CrossRef]

2. $\mathrm{Hu}, \mathrm{M} . ; \mathrm{Li}$, L.; Peng, F. Laboratory investigation of ogfc-5 porous asphalt ultra-thin wearing course. Constr. Build. Mater. 2019, 219, 101-110. [CrossRef]

3. Son, S.; Al-Qadi, I.L.; Zehr, T. $4.75 \mathrm{~mm}$ sma performance and cost-effectiveness for asphalt thin overlays. Int. J. Pavement Eng. 2016, 17, 799-809. [CrossRef]

4. Editorial Department of China Journal of Highway and Transport. Review on China's pavement engineering research·2020. China J. Highw. Transp. 2020, 33, 1-66. [CrossRef]

5. Chen, F. Research on Mechanical and Functional Properties of High-Toughness Ultra-Thin Friction Course. Master's Thesis, South China University of Technology, Guangdong, China, 2020. Available online: https://kns.cnki.net/KCMS/detail/detail. aspx?dbname=CMFD202101\&filename $=1020332780$. nh (accessed on 8 May 2021). 
6. Bellanger, J.; Brosseaud, Y.; Gourdon, J.L. Thinner and Thinner Asphalt Layers for the Maintenanee of Freneh Roads. Transp. Res. Rec. 1992, 1334, 9-11. Available online: https://onlinepubs.trb.org/Onlinepubs/trr/1992/1334/1334-002.pdf (accessed on 8 May 2021).

7. Jahren, C.; Behling, K. Thin Maintenance Surface Treatments: Comparative Study. Transp. Res. Rec. J. Transp. Res. Board 2004, 1866, 20-27. [CrossRef]

8. Putman, B.J.; Amirkhanian, S. Utilization of waste fibers in stone matrix asphalt mixtures. Resour. Conserv. Recycl. 2004, 42, 265-274. [CrossRef]

9. Coleri, E.; Harvey, J.T.; Yang, K.; Boone, J.M. Micromechanical investigation of open-graded asphalt friction courses' rutting mechanisms. Constr. Build. Mater. 2013, 44, 25-34. [CrossRef]

10. Bennert, T.; Fee, F.; Sheehy, E.; Jumikis, A.; Sauber, R. Comparison of Thin-Lift Hot-Mix Asphalt Surface Course Mixes in New Jersey. Transp. Res. Rec. J. Transp. Res. Board 2005, 1929, 59-68. [CrossRef]

11. Rahaman, F.; Musty, H.; Hossain, M. Evaluation of Recycled Asphalt Pavement Materials from Ultra-Thin Bonded Bituminous Surface. In Proceedings of the GeoCongress 2012, Oakland, CA, USA, 25-29 March 2012. [CrossRef]

12. Beyene, M.A.; Meininger, R.C.; Gibson, N.H.; Muñoz, J.F.; Youtcheff, J. Forensic investigation of the cause(s) of slippery ultra-thin bonded wearing course of an asphalt pavement: Influence of aggregate mineralogical compositions. Int. J. Pavement Eng. 2015, 17, 887-900. [CrossRef]

13. Zuo, Q. Research on Application Technology of Thin Overlay with LASTIKA Asphalt Concrete. Master's Thesis, Changsha University of Science and Technology, Changsha, China, 2007. Available online: https://kns.cnki.net/KCMS/detail/detail.aspx? dbname=CMFD2008\&filename=2007205909.nh (accessed on 17 June 2021).

14. Yang, X. Research on Technology of Ultrathin Asphalt Friction Course. Master's Thesis, Chang'an University, Xi'an, China, 2011. Available online: https:/ / kns.cnki.net/KCMS/detail/detail.aspx?dbname=CMFD201402\&filename=1013019398.nh (accessed on 8 May 2021).

15. Yu, J.; Chen, F.; Deng, W.; Ma, Y.; Yu, H. Design and performance of high-toughness ultra-thin friction course in south China. Constr. Build. Mater. 2020, 246, 118508. [CrossRef]

16. Paniagua, F.; Paniagua, J.; Mateos, A.; Wu, R.; Harvey, J.T. Full-Scale Evaluation of Concrete-Asphalt Interphase in Thin Bonded Concrete Overlay on Asphalt Pavements. Transp. Res. Rec. J. Transp. Res. Board 2020, 2674, 676-686. [CrossRef]

17. Mateos, A.; Harvey, J.; Paniagua, J.; Paniagua, F.; Liu, A.F. Mechanical characterisation of concrete-asphalt interface in bonded concrete overlays of asphalt pavements. Eur. J. Environ. Civ. Eng. 2017, 21, 43-53. [CrossRef]

18. Sachs, S.G.; Vandenbossche, J.M.; Li, Z.; Barman, M. Accounting for Temperature Susceptibility of Asphalt Stiffness When Designing Bonded Concrete Overlays of Asphalt Pavements. J. Transp. Eng. 2016, 142, 04016040. [CrossRef]

19. Qin, X.; Zhu, S.; He, X.; Jiang, Y. High temperature properties of high viscosity asphalt based on rheological methods. Constr. Build. Mater. 2018, 186, 476-483. [CrossRef]

20. Li, M.; Zeng, F.; Xu, R.; Cao, D.; Li, J. Study on Compatibility and Rheological Properties of High-Viscosity Modified Asphalt Prepared from Low-Grade Asphalt. Materials 2019, 12, 3776. [CrossRef] [PubMed]

21. Chen, S.; Dou, H.; Xing, M.; He, R.; Liu, Z. Study on the rheological properties of high temperature asphalt mortat with high viscosity of TPS. J. Xi'an Univ. Archit. Technol. 2014, 46, 380-384. [CrossRef]

22. Wang, T.; Wei, X.; Zhang, D.; Shi, H.; Cheng, Z. Evaluation for Low Temperature Performance of SBS Modified Asphalt by Dynamic Shear Rheometer Method. Buildings 2021, 11, 408. [CrossRef]

23. Yu, H.; Leng, Z.; Dong, Z.; Tan, Z.; Guo, F.; Yan, J. Workability and mechanical property characterization of asphalt rubber mixtures modified with various warm mix asphalt additives. Constr. Build. Mater. 2018, 175, 392-401. [CrossRef]

24. Jin, J.; Gao, Y.; Wu, Y.; Liu, S.; Liu, R.; Wei, H.; Qian, G.; Zheng, J. Rheological and adhesion properties of nano-organic palygorskite and linear SBS on the composite modified asphalt. Powder Technol. 2020, 377, 212-221. [CrossRef]

25. Yu, H.; Deng, G.; Zhang, Z.; Zhu, M.; Gong, M.; Oeser, M. Workability of rubberized asphalt from a perspective of particle effect. Transp. Res. Part D Transp. Environ. 2021, 91, 102712. [CrossRef]

26. Yang, W. Study on Performance and Application of Asphalt Warm Mix Agent Based on Surface Active Technology. Master's Thesis, Dalian University of Technology, Dalian, China, 2019. Available online: https://kns.cnki.net/KCMS/detail/detail.aspx? dbname $=C M F D 202001 \&$ filename $=1019865384$. nh (accessed on 17 June 2021).

27. Yu, H.; Leng, Z.; Xiao, F.; Gao, Z. Rheological and chemical characteristics of rubberized binders with non-foaming warm mix additives. Constr. Build. Mater. 2016, 111, 671-678. [CrossRef]

28. Yu, H.; Leng, Z.; Zhou, Z.; Shih, K.; Xiao, F.; Gao, Z. Optimization of preparation procedure of liquid warm mix additive modified asphalt rubber. J. Clean. Prod. 2017, 141, 336-345. [CrossRef]

29. Jin, J.; Liu, S.; Gao, Y.; Liu, R.; Huang, W.; Wang, L.; Xiao, T.; Lin, F.; Xu, L.; Zheng, J. Fabrication of cooling asphalt pavement by novel material and its thermodynamics model. Constr. Build. Mater. 2020, 272, 121930. [CrossRef]

30. Yu, H.; Zhu, Z.; Leng, Z.; Wu, C.; Zhang, Z.; Wang, D.; Oeser, M. Effect of mixing sequence on asphalt mixtures containing waste tire rubber and warm mix surfactants. J. Clean. Prod. 2019, 246, 119008. [CrossRef]

31. Jin, J.; Gao, Y.; Wu, Y.; Li, R.; Liu, R.; Wei, H.; Qian, G.; Zheng, J. Performance evaluation of surface-organic grafting on the palygorskite nanofiber for the modification of asphalt. Constr. Build. Mater. 2020, 268, 121072. [CrossRef]

32. Chelelgo, K.; Gariy, Z.C.A.; Shitote, S.M. Laboratory Mix Design of Cold Bitumen Emulsion Mixtures Incorporating Reclaimed Asphalt and Virgin Aggregates. Buildings 2018, 8, 177. [CrossRef] 
33. Zalnezhad, M.; Hesami, E. Effect of steel slag aggregate and bitumen emulsion types on the performance of microsurfacing mixture. J. Traffic Transp. Eng. 2019, 7, 215-226. [CrossRef]

34. Han, S.; Yao, T.; Han, X.; Hongwei, Z.; Yang, X. Performance evaluation of waterborne epoxy resin modified hydrophobic emulsified asphalt micro-surfacing mixture. Constr. Build. Mater. 2020, 249, 118835. [CrossRef]

35. ASTM D5-06E1. Standard Test Method for Penetration of Bituminous Materials; ASTM International: West Conshohocken, PA, USA, 2006.

36. ASTM D36-06. Standard Test Method for Softening Point of Bitumen (Ring-and-Ball Apparatus); ASTM International: West Conshohocken, PA, USA, 2006.

37. ASTM D6084/D6084M-21. Standard Test Method for Elastic Recovery of Asphalt Materials by Ductilometer; ASTM International: West Conshohocken, PA, USA, 2021.

38. ASTM D2042-01. Standard Test Method for Solubility of Asphalt Materials in Trichloroethylene; ASTM International: West Conshohocken, PA, USA, 2001.

39. ASTM D5-06E1976. Standard Specification for Type I Polymer Modified Asphalt Cement for Use in Pavement Construction; ASTM International: West Conshohocken, PA, USA, 2000.

40. ASTM D6373-21A. Standard Specification for Performance-Graded Asphalt Binder; ASTM International: West Conshohocken, PA, USA, 2021.

41. ASTM D2171-07E1. Standard Test Method for Viscosity of Asphalts by Vacuum Capillary Viscometer; ASTM International: West Conshohocken, PA, USA, 2007.

42. ASTM D2872-04. Standard Test Method for Effect of Heat and Air on a Moving Film of Asphalt (Rolling Thin-Film Oven Test); ASTM International: West Conshohocken, PA, USA, 2004.

43. ASTM D7175-15. Standard Test Method for Determining the Rheological Properties of Asphalt Binder Using a Dynamic Shear Rheometer; ASTM International: West Conshohocken, PA, USA, 2015.

44. AASHTO T59. Standard Method of Test for Emulsified Asphalts; American Association of State and Highway Transportation Officials: Washington, DC, USA, 2013.

45. JTG E20-2011. Standard Test Methods of Bitumen and Bituminous Mixtures for Highway Engineering; Ministry of Transport of the People's Republic China: Beijing, China, 2011.

46. ASTM D113-07. Standard Test Method for Ductility of Bituminous Materials (Withdrawn 2016); ASTM International: West Conshohocken, PA, USA, 2007.

47. ASTM D5821-13. Standard Test Method for Determining the Percentage of Fractured Particles in Coarse Aggregate; ASTM International: West Conshohocken, PA, USA, 2017.

48. ASTM C131-01. Standard Test Method for Resistance to Degradation of Small-Size Coarse Aggregate by Abrasion and Impact in the Los Angeles Machine; ASTM International: West Conshohocken, PA, USA, 2001.

49. ASTM C127-12. Standard Test Method for Density, Relative Density (Specific Gravity), and Absorption of Coarse Aggregate; ASTM International: West Conshohocken, PA, USA, 2012.

50. ASTM C88/C88M-18. Standard Test Method for Soundness of Aggregates by Use of Sodium Sulfate or Magnesium Sulfate; ASTM International: West Conshohocken, PA, USA, 2018.

51. ASTM D4791-19. Standard Test Method for Flat Particles, Elongated Particles, or Flat and Elongated Particles in Coarse Aggregate; ASTM International: West Conshohocken, PA, USA, 2019.

52. ASTM C136. Standard Test Method for Sieve Analysis of Fine and Coarse Aggregates; ASTM International: West Conshohocken, PA, USA, 2019.

53. ASTM D3319. Standard Practice for the Accelerated Polishing of Aggregates Using the British Wheel; ASTM International: West Conshohocken, PA, USA, 2017.

54. ASTM C128-12. Standard Test Method for Density, Relative Density (Specific Gravity), and Absorption of Fine Aggregate; ASTM International: West Conshohocken, PA, USA, 2012.

55. ASTM D2419-14. Standard Test Method for Sand Equivalent Value of Soils and Fine Aggregate; ASTM International: West Conshohocken, PA, USA, 2014.

56. ASTM D6307-19. Standard Test Method for Asphalt Content of Asphalt Mixture by Ignition Method; ASTM International: West Conshohocken, PA, USA, 2019.

57. ASTM D5581-07A. Standard Test Method for Resistance to Plastic Flow of Bituminous Mixtures Using Marshall Apparatus (6 InchDiameter Specimen); ASTM International: West Conshohocken, PA, USA, 2013.

58. AASHTO T283. Standard Method of Test for Resistance of Compacted Hot Mix Asphalt (HMA) to Moisture-Induced Damage; American Association of State and Highway Transportation Officials: Washington, DC, USA, 2011.

59. ASTM D8292-20. Standard Test Method for Permanent Deformation Behavior and Rutting Resistance of Compacted Asphalt Mix in the Modified Loaded Wheel Tracker Test Utilizing Controlled Confining Pressure; ASTM International: West Conshohocken, PA, USA, 2020.

60. ASTM D7064/D7064M-21. Standard Practice for Open-Graded Friction Course (OGFC) Asphalt Mixture Design; ASTM International: West Conshohocken, PA, USA, 2021.

61. ASTM E965. Standard Test Method for Measuring Pavement Macro texture Depth Using a Volumetric Technique; ASTM International: West Conshohocken, PA, USA, 2015. 
62. ASTM C293/C293M-16. Standard Test Method for Flexural Strength of Concrete (Using Simple Beam with Center-Point Loading); ASTM International: West Conshohocken, PA, USA, 2016.

63. Zhang, X.; Zou, G.; He, Z. Study on evaluation method of resistance to reflection Crack of asphalt mixture. J. South China Univ. Technol. 2001, 29, 88-91. Available online: https:// kns.cnki.net/KCMS/detail/detail.aspx?dbname=SNAD\&filename=SNAD000 001305767 (accessed on 17 June 2021).

64. ASTM D8044-16. Standard Test Method for Evaluation of Asphalt Mixture Cracking Resistance using the Semi-Circular Bend Test (SCB) at Intermediate Temperatures; ASTM International: West Conshohocken, PA, USA, 2016.

65. ASTM D8237-21. Standard Test Method for Determining Fatigue Failure of Asphalt-Aggregate Mixtures with the Four-Point Beam Fatigue Device; ASTM International: West Conshohocken, PA, USA, 2021.

66. ASTM E303. Standard Test Method for Measuring Surface Frictional Properties Using the British Pendulum Tester; ASTM International: West Conshohocken, PA, USA, 2018.

67. JTG 3450-2019. Test Method for Water Seepage Coefficient of Asphalt Pavement; Ministry of Transport of the People's Republic of China: Beijing, China, 2019.

68. ASTM D4541. Standard Test Method for Pull-Off Strength of Coatings Using Portable Adhesion Testers; ASTM International: West Conshohocken, PA, USA, 2018. 